\title{
Выбор условий сорбционного концентрирования фенолов из потока воздуха на поверхностно-слойных угольно-фторопластовых сорбентах для их последующего ВЭЖХ определения
}

\author{
(с) 2020 Родинков О. В., Спиваковский В., Москвин Л.Н. \\ Санкт-Петербургский государственный университет, Институт химии, Санкт-Петербург
}

Поступила в редакцию 10.02.2020 г.

DOI: $10.17308 /$ sorpchrom.2020.20/2773

Фенол и изомерные крезолы относятся к распространенным высокотоксичным загрязнителям атмосферного воздуха, для определения которых требуются высокоэффективные методы концентрирования. Цель настоящей работы - выбор условий экспрессного сорбционного концентрирования фенолов из потока воздуха на поверхностно-слойных угольно-фторопластовых сорбентах для их последующего ВЭЖХ определения на уровне предельно допустимых концентраций. Указанная цель достигается за счет применения поверхностно-слойных угольно-фторопластовых сорбентов. В качестве оптимального углеродного сорбента выбран активный уголь ФАД, обеспечивающий максимальные объемы удерживания фенола из потока анализируемого воздуха. Для оценки эффективности исследуемых сорбентов использовали модельные газовые смеси с постоянной концентрацией фенолов $50 \mathrm{Mг} / \mathrm{M}^{3}$. Эти смеси получали путем пропускания потока воздуха через водные растворы с известной концентрацией фенолов. Установлено, что в выбранном диапазоне объемных скоростей потока воздуха (100-500) см³/мин обеспечивалось равновесное распределение фенолов между фазами и постоянство их концентрации в газовой фазе в процессе выполнения эксперимента.

Установлено, что при прочих равных условиях разработанные поверхностно-слойные сорбенты позволяют в 2-3 раза повысить степень концентрирования фенолов и в 1.5-2 раза сократить продолжительность стадии сорбционного концентрирования по сравнению с традиционными объемно-пористыми активными углями. При реализации методики анализа 15 литров анализируемого воздуха пропускали через сорбционную колонку со скоростью потока 0.5 дм $3 /$ мин в течение 30 минут. Десорбцию фенолов осуществляли непосредственно из сорбционной колонки с помощью $1.5 \mathrm{~cm}^{3}$ ацетонитрила, который анализировали в обращенно-фазовой варианте ВЭЖХ с флуориметрическим детектором. Нижняя граница диапазона определяемых концентраций фенола и изомер-

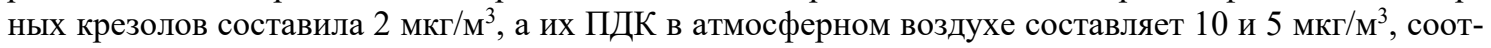
ветственно.

Ключевые слова: фенол, крезолы, воздух, концентрирование, сорбенты, поверхностнослойные, угольно-фторопластовые, ВЭЖХ

\section{Введение}

К числу распространенных высокотоксичных загрязнителей воздуха относятся фенол и изомерные крезолы, для определения которых на уровне ПДК требуются высокоэффективные методы концентрирования [1]. К наиболее эффективным методам относится сорбция, которую в последние годы принято называть твердофазной экстракцией (ТФЭ) [2,3]. Возможности последней в её наиболее распространенном варианте твердофазной микроэкстракции ограничены небольшой массой сорбирующей фазы (0.2-2 мг), и, соответственно, относительно небольшими 
количествами сорбируемых аналитов, недостаточными для достижения низких пределов обнаружения [4,5].

С точки зрения достигаемых пределов обнаружения предпочтительнее динамическая ТФЭ, основанная на пропускании анализируемого газа через колонку с сорбентом, с последующей термодесорбцией или десорбцией органическим растворителем аналитов и их хроматографическим определением [2,6]. К настоящему времени для реализации ТФЭ предложены самые различные сорбенты [7-9], включая углеродные и наноуглеродные [10] с различной удельной поверхностью и гидрофобностью. Наряду с более высокой термостойскостью углеродные сорбенты обладают значительно более высокой адсорбционной способностью по отношению к органическим соединениям в сравнении с полимерными сорбентами с той же удельной поверхностью, что находит теоретическое объяснение [11]. При концентрировании фенолов существенным недостатком сорбентов с высокой удельной поверхностью, включая углеродные, является невозможность применения термодесорбции $[12,13]$, обеспечивающей в случае газохроматографического определения многократно более низкие пределы обнаружения аналитов. Однако, если десорбировать фенолы непосредственно из сорбционной колонки органическим растворителем, совместимым с их последующим ВЭЖХ определением и флуориметрическим детектированием, то достигаемые при этом пределы обнаружения аналитов не хуже [14], чем в случае их термодесорбции с полимерного адсорбента и последующего газохроматографического определения с масс-спектрометрическим детектированием [15].

Закономерности ТФЭ из газовой фазы изучены достаточно подробно и нашли отражение в международном стандарте [12]. Независимо от используемого сорбента общим недостатком ТФЭ на традиционных объемно-пористых сорбентах, использование которых предписывает этот стандарт, является относительно невысокая скорость массообмена, которая ограничивает допустимую скорость пропускания анализируемого воздуха через сорбционную колонку и является причиной большой продолжительности стадии сорбционного концентрирования. Например, время сорбционного концентрирования фенола из необходимых для анализа 10 литров воздуха составляет около 50 минут при максимально допустимом расходе воздуха $200 \mathrm{~cm}^{3} /$ мин через колонку, заполненную рекомендуемым полимерным сорбентом Tenax TA.

Значительного повышения экспрессности сорбционного концентрирования можно добиться за счет применения поверхностно-слойных сорбентов (ПСС), в которых мелкодисперсный сорбционно-активный материал, находится в порах относительно крупнодисперсного носителя [16]. Подобное сочетание обеспечивает, с одной стороны, высокую эффективность массообмена, а с другой - высокую проницаемость сорбционного слоя, необходимую для экспрессного динамического концентрирования при пропускании анализируемого воздуха через сорбционную колонку с высокой скоростью. Для сорбционного концентрирования аналитов из газовой фазы относительно недавно были предложены поверхностно-слойные угольно-фторопластовые сорбенты [17]. Однако проведенные до настоящего времени исследования $[17,18]$ относились к концентрированию исключительно легколетучих органических соединений (низшие спирты и кетоны, углеводороды) с ориентацией на их последующую термодесорбцию и газохроматографическое определение. Выбор политетрафторэтилена (фторопласта-4) в качестве носителя связан с его высокой адгезионной способностью по отношению к микрочастицам активного угля, в отличие от микрочастиц полимерных сорбентов [19]. 
Цель настоящей работы - выбор условий экспрессного сорбционного концентрирования фенолов из потока воздуха на поверхностно-слойных угольно-фторопластовых сорбентах для их последующего ВЭЖХ определения на уровне ПДК.

\section{Эксперимент}

Получение поверхностно-слойных угольно-фторопластовых сорбентов. Эти сорбенты получали суспензионным способом [19]. К навеске мелкоизмельченного активного угля (размер частиц менее 40 мкм), находящегося в виде суспензии в этаноле, при постоянном перемешивании мелкими порциями добавляли навеску пористого политетрафторэтилена (размер части 0.5-1 мм), а затем выпаривали этанол до постоянной массы сорбента. На заключительной стадии ПСС просеивали через сито с размером ячеек 100 мкм, отделяя полученный сорбент от микрочастиц угля, не удержанных фторопластовым носителем. После этого взвешиванием определяли массу угля, зафиксированного на носителе.

Оценка порометрических показателей сорбентов. Важнейшими показателями пористой структуры сорбентов, от которых зависит их способность к удерживанию фенолов, являются распределение пор по размерам, удельная поверхность и удельный объем пор [20]. Для измерения этих показателей использовался адсорбционно-структурный метод, основанный на физической адсорбции газообразного азота при температуре $77 \mathrm{~K}$, осуществляемый по стандартной методике [21]. Перед измерениями образцы сорбентов подвергали дегазации в вакууме при $300^{\circ} \mathrm{C}$ в течение 10 часов для удаления сорбированных газов и воды.

Получение модельных газовых смесей. Для оценки эффективности исследуемых сорбентов использовали модельные газовые смеси с постоянной концентрацией фенолов 50 мг/м ${ }^{3}$. Эти смеси получали путем пропускания потока воздуха через водные растворы с заданной концентрацией этих веществ с чистотой не ниже «чда» или «ч» [22]. Установлено, что в выбранном диапазоне объемных скоростей потока воздуха 100-500 cm 3 мин обеспечивалось равновесное распределение тестовых веществ между фазами и постоянство их концентрации в газовой фазе. Об этом можно судить по постоянству концентрации аналитов в потоке модельных газовых смесей, получаемых при различных скоростях потоках воздуха. Концентрацию фенолов в модельных газовых смесях с рассчитывали по формуле:

$$
C=\frac{C_{L}}{K}
$$

где $c_{L}$ - концентрация тестового вещества в растворе, $K$ - его коэффициент распределения между жидкой и газовой фазами, равный отношению концентрации тестового вещества в жидкой фазе к его концентрации в газовой фазе при равновесии. Значения $K$ определяли по известной методике [23].

Оценка аналитических возможностей сорбентов. Для оценки сорбционной емкости исследуемых сорбентов через колонки, заполненные навесками этих сорбентов, пропускали модельные газовые смеси фенолов с заданным расходом $\left(W_{G}\right)$. Для контроля полноты сорбции отбирали порции газовой фазы на выходе из колонки и с помощью газового хроматографа определяли в них концентрации фенолов. Строили выходные кривые удерживания тестовых веществ в виде зависимостей $c / c_{0}$ от $V$, где $c$ и $c_{0}-$ концентрация тестового вещества в газовой фазе на выходе из колонки и на входе в нее, соответственно; $V$ - объем модельной газовой смеси, пропущенной через колонку. Из полученных кривых для каждого тестового вещества определяли объем до проскока $\left(V_{\mathrm{B}}\right)$ и объем удерживания $\left(V_{\mathrm{R}}\right)$. За величину $V_{\mathrm{B}}$ 
принимали объем газовой смеси, пропущенной через колонку $(V)$, который соответствует 95\% -ому извлечению аналита. За величину $V_{R}$ принимали объем пропущенной через колонку газовой смеси, для которого выполняется условие: $c / c 0=0.5$.

С целью выбора условий десорбции аналитов из колонки, сконцентрированные в сорбционной колонке фенолы десорбировали ацетонитрилом, выбранным в качестве компонента элюента, исходя из условия его совместимости с обращенно-фазовым вариантом ВЭЖХ и использования флуориметрического детектора. По результатам определения концентрации фенолов в последовательных порциях ацетонитрила на выходе из колонки строили кривые десорбции в виде зависимостей $c$ от $V$, где $c$ - концентрация аналита в растворителе на выходе из колонки, а $V$ - объем растворителя, пропущенного через колонку. Исходя из построенных кривых десорбции, оценивали объем ацетонитрила, необходимый для 95\%-ной десорбции фенолов.

Оборудование. Порометрические исследования изучаемых сорбентов проводили на волюметрическом адсорбомере Micromeritics ASAP 2020 MP (производство «Micromeritics», США). Регулирование потока воздуха при получении модельных газовых смесей осуществляли с помощью автономного формирователя газовых потоков «Хроматэк-Кристалл ФГП». Определение фенолов в газовой фазе выполняли с помощью газового хроматографа «Кристалл-5000.2» (производство «Хроматэк», Россия) снабженного пламенно-ионизационным детектором и капиллярной колонкой (10 м×0.53 мм $\times 2.65$ мм) BPX-1 (100\% диметилполисилоксан). ВЭЖХ определение тестовых веществ выполняли на жидкостном хроматографе Shimadzu LC-20 Prominence с флуориметрическим детектором Shimadzu RF-20A и хроматографической колонкой (длина ×внутренний диаметр) $250 \times 4.6$ мм, заполненной сорбентом Supelco Discovery $\mathrm{C}_{18}$ с размерами частиц 5 мкм. Температура колонки $-30^{\circ} \mathrm{C}$. Длина волны возбуждения - 215 нм, длина волны излучения 300 нм.

\section{Обсуждение результатов}

Выбор наиболее эффективного сорбционно-активного углеродного материала. Сопоставление параметров удерживания фенола на различных углеродных сорбентах показало (табл. 1), что максимальные параметры удерживания обеспечивает активный уголь ФАД, обладающий также наибольшей удельной поверхностью и максимальным объемом микропор.

Таблица 1. Характеристики исследованных углеродных адсорбентов. $\mathrm{VR}_{\mathrm{R}(\mathrm{y})}-$ удель-

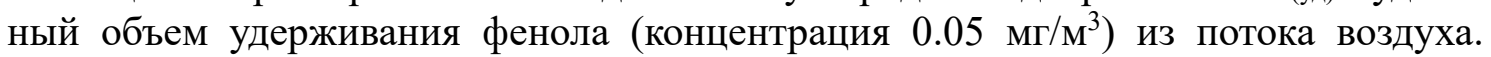
АУ - активный уголь, ЭХЗ - экспериментальный химический завод.

\begin{tabular}{|c|c|c|c|}
\hline АдсорбенТ, производитель & $\begin{array}{c}\text { Удельная по- } \\
\text { верхность, } \mathrm{m}^{2} / \Gamma\end{array}$ & $\begin{array}{c}\text { Удельный объем } \\
\text { микропор, } \mathrm{cm}^{3} / \Gamma\end{array}$ & $\mathrm{V}_{\mathrm{R}(\mathrm{y})}, \mathrm{M}^{3} / \Gamma$ \\
\hline АУ БАУ, ЗАО «ЭХЗ» & 750 & 0.270 & $3.2 \pm 0.2$ \\
\hline АУ СКТ, АО «Сорбент» & 860 & 0.310 & $2.7 \pm 0.1$ \\
\hline АУ ФАС, ЭНПО “Неорганика” & 1400 & 0.510 & $5.1 \pm 0.3$ \\
\hline АУ ФАД, ЭНПО “Неорганика” & 1500 & 0.530 & $5.6 \pm 0.3$ \\
\hline Сarboхеn 1000, Supelko Inc. & 880 & 0.310 & $2.9 \pm 0.2$ \\
\hline Нанотрубки, «Bayer» & 270 & - & $0.46 \pm 0.02$ \\
\hline Carbopack В, Supelko Inc. & 90 & - & $0.31 \pm 0.02$ \\
\hline
\end{tabular}


В отличие от активных углей БАУ и СКТ, которые получают из природного сырья, угли ФАД и ФАС производят из термопластных полимеров на основе фурфурола. Мезопористые сорбенты (нанотрубки и карбопак В), которые были выбраны в качестве объектов исследования с точки зрения проверки возможности термодесорбции, по сорбционной емкости значительно уступают активным углям.

Сравнение эффективности объемно-пористых сорбентов и ПСС. На основе активных углей ФАД и БАУ были получены ПСС с содержанием активных углей $15-32 \%$ от массы фторопластового носителя. Выбор БАУ обусловлен тем, что уступая углю ФАД по параметрам удерживания фенола (см. табл. 1), он, как было установлено на предыдущих этапах проекта, значительно гидрофобнее, чем ФАД. Это свойство могло бы стать важным преимуществом при анализе влажного воздуха. Установлено, что параметры удерживания фенолов возрастают прямо пропорционально содержанию активного угля в ПСС. Для того, чтобы исключить влияние размеров частиц на результаты сравнения эффективности сорбции во всех случаях использовали сорбенты одного и того же гранулометрического состава - (0.45-0.9) мм. Подобные размеры частиц обеспечивают высокую эффективность массообменного процесса при достаточно высоких скоростях потока анализируемого воздуха через сорбционную колонку, создаваемых с помощью серийно выпускаемых электроаспираторов [24].

На стадии сорбции преимущества ПСС начинают проявляться при высоких расходах анализируемого воздуха через сорбционную колонку (более $200 \mathrm{~cm}^{3} /$ мин) и заключаются в значительном увеличении объемов до проскока сорбируемых фенольных соединений. В качестве иллюстрации на рис. 1 представлены выходные кривые удерживания фенола из потока воздуха на исходных угольных сорбентах и ПСС на их основе. Аналогичные преимущества ПСС были установлены и в случае изомерных крезолов.

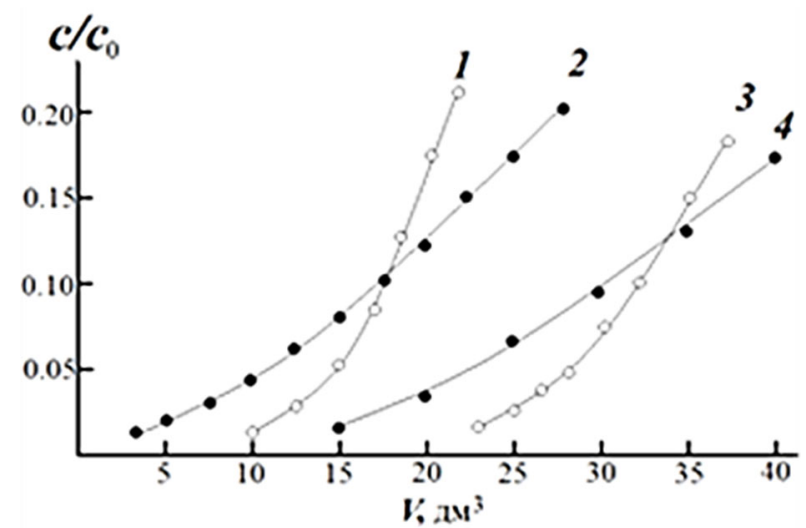

Рис. 1. Начальные участки выходных кривых удерживания фенола из потока воздуха $500 \mathrm{~cm}^{3} /$ мин в сорбционных колонках $(3 \times 0.3 \mathrm{~cm})$, заполненных активными углями: БАУ (2) и ФАД (4), а также ПСС на их основе с содержанием углей $30 \%$ : 1 - БАУ, 3 - ФАД. $C$ и $C_{0}$-концентраций фенола в потоке воздуха на выходе и входе в сорбционную колонку; $V$ - объем воздуха, пропущенного через колонку

Для того, чтобы на обычных сорбентах получить такие же объемы до проскока $V_{B}$, как на ПСС, необходимо уменьшить скорость потока воздуха через сорбционную колонку с $500 \mathrm{~cm}^{3} /$ мин до (250-300) $\mathrm{cm}^{3} /$ мин. Иными словами, при прочих равных условиях ПСС позволяют приблизительно в 1.5-2 раза снизить продолжительность стадии сорбционного концентрирования фенолов из воздуха. 
Значительные преимущества ПСС проявляются и на стадии десорбции. На рис. 2 приведены кривые десорбции фенолов с помощью ацетонитрила из колонок, заполненных равными объемами активного угля ФАД и ПСС на его основе. Как видно из рис. 2 , применение ПСС позволяет в 2-3 раза сократить объем органического растворителя, необходимый для количественной десорбции сконцентрированных фенолов. При прочих равных условиях это дает возможность в 2-3 раза снизить пределы обнаружения аналитов.

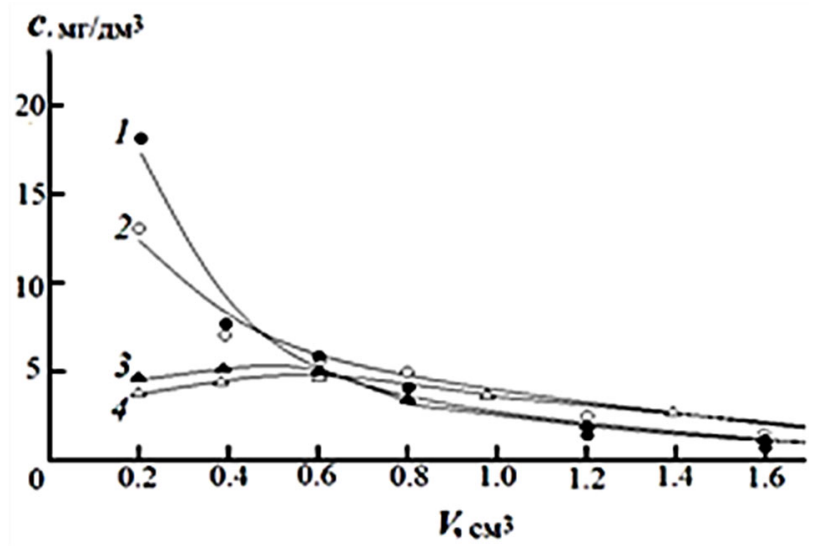

Рис. 2. Кривые десорбции с помощью ацетонитрила фенола $(1,3)$ и о-крезола $(2,4)$ из колонок $(3 \times 0.3$ см), заполненных ПСС, содержащим $30 \%$ ФАД $(1,2)$, и чистым углем ФАД $(3,4) . C$ - концентрация фенолов в ацетонитриле на выходе из колонки; $V$ - объем ацетонитрила, пропущенного колонку

Среди всех возможных органических растворителей, пригодных для количественной десорбции сорбированных фенолов, предпочтительнее применение ацетонитрила, поскольку он используется в качестве основного компонента подвижной жидкой фазы при ВЭЖХ определении фенольных соединений в обращенно-фазовом варианте этого метода. Следует отметить, что десорбция органическим растворителем имеет ряд преимуществ по сравнению с термодесорбцией: возможность многократного анализа концентрата, отсутствие негативного влияния накопленного при сорбции водяного пара.

Результаты проведенных исследований свидетельствуют о том, что ПСС позволяют в 2-3 раза повысить степень концентрирования фенола и изомерных крезолов при анализе воздуха и в 1.5-2 раза сократить продолжительность стадии сорбционного концентрирования по сравнению с традиционными объемно-пористыми активными углями.

Оценка метрологических характеристик разработанной схемы анализа. Применение ПСС на основе активного угля ФАД обеспечивает концентрирование фенольных соединений из потока воздуха в $10^{4}$ раз за 30 минут при скорости потока

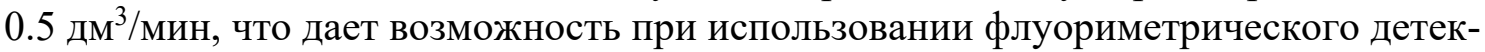
тора проводить их ВЭЖХ определение на уровне ПДК для атмосферного воздуха

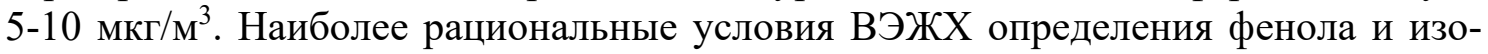
мерных крезолов были установлены нами ранее [25]. При использовании градиентного элюирования возможно раздельное определение $o$-крезола и суммы $\mathcal{M}$ - и $n$ крезолов. Время анализа не превышает 8 минут. Поскольку все крезолы имеют одну и ту же ПДК [26], их раздельное определение не обязательно, а время анализа можно сократить до 4 минут используя изократическое разделение при объемном содержании ацетонитрила 50\%. 
Полное извлечение аналитов на стадиях сорбции и десорбции позволяет для расчета их массовой концентрации в анализируемом воздухе (c) использовать метод абсолютной градуировки и рассчитывать их концентрации по формуле:

$$
c=\frac{s}{k V_{G}}
$$

где $S$ - площадь пика аналита на хроматограмме мB·c; $k$ - градуировочный коэффициент, (мВ·c)/мкг; $V_{G}$ - объем анализируемого воздуха, пропущенного через сорбционную колонку, дм ${ }^{3}$. Градуировочные зависимости площади пиков от массы аналитов, введенных в хроматограф, во всем исследуемом диапазоне (до 10 мкг) представляют собой прямые линии, проходящие через начало координат. Подобные зависимости характерны для флуориметрического детектора. Сопоставление экспериментально найденных по формуле (2) и рассчитанных по формуле (1) концентраций аналитов (метод «введено-найдено») свидетельствует о незначимости методической составляющей систематической погрешности на фоне случайного разброса результатов.

Выбранная схема сорбционного концентрирования обеспечивает высокую повторяемость результатов анализа. Относительное стандартное отклонение в серии параллельных определений не превышает $3 \%$ при использовании в качестве аналитического сигнала высоты пика и $2 \%$ - площади пика.

\section{Заключение}

Выбраны необходимые условия сорбционного концентрирования фенола и изомерных крезолов из воздуха на поверхностно-слойных угольно-фторопластовых сорбентах для их последующего ВЭЖХ определения в обращенно-фазовом варианте метода с флуориметрическим детектированием. Использование предложенных сорбентов позволяет в 1.5-2 раза сократить продолжительность стадии сорбционного концентрирования и в 2-3 раза снизить пределы обнаружения аналитов по сравнению с традиционными объемно-пористыми угольными сорбентами того же гранулометрического состава. Нижняя граница диапазона определяемых концентраций фенола и изомерных крезолов составляет 2 мкг $/ \mathrm{M}^{3}$, а их ПДК в атмосферном воздухе 10 и 5 мкг/ $\mathrm{M}^{3}$, соответственно.

Работа выполнена при поддержке Российского научного фонда (грант № 16-13-10117-П) с использованием оборудования РЦ СПбГУ «Методы анализа состава вещества» и РЦ СПбГУ «Инновационные технологии композитных наноматериалов».

\section{Список литературы}

1. Другов Ю.С., Конопелько Л.А., Попов О.Г. Контроль загрязнений воздуха жилых помещений, офисов, административных и общественных зданий. СПб.: Наука. 2013. $302 \mathrm{c}$.

2. Poole C., Mester Z., Miró M., PedersenBjergaard S., Pawliszyn J. // Pur. Appl. Chem. 2016. Vol. 88. No 7. pp. 649-687.

3. Woolfenden E. // J. Chromatogr. A. 2010. Vol. 1217. pp. 2674-2694.
4. Piri-Moghadam H., Ahmadi F., Pawliszyn J. // Trend. Anal. Chem. 2016. Vol. 85. pp. 133143.

5. Родинков О.В., Журавлёва Г.А. // Аналитика. 2019. Т. 9. № 1. С. 48-58. DOI: 10.22184/2227-572X.2019.09.1.48.58

6. Andrade-Eiroa A., Canle M., Leroy-Cancellieri V., Cerdà V. // Trends Anal. Chem. 2016. Vol. 80. pp. 641-654. DOI: 10.1016/j.trac.2015.08.015 
7. Płotka-Wasylka J., Szczepańska N., Guardia M., Namieśnik J. // Trends Anal. Chem. 2016. Vol. 77. pp. 23-43.

8. Mastrogiacomo A.R., Ottaviani M.F., Pierini E., Cangiotti M., Mauro M., Mangani F. // Chromatographia. 2002. Vol. 55. No 5,6. pp. 345-348.

9. Постнов В.Н., Родинков О.В., Москвин Л.Н., Новиков А.Г. и др. // Успехи химии. 2016. Т. 85. № 2. С. 115-138.

10. Жейвот В.И. // Журн. аналит. химии. 2006. Т. 61. № 9. С. 902-924.

11. ГОСТ Р ИСО 16017-1-2007. Воздух атмосферный, рабочей зоны и замкнутых помещений. Отбор проб летучих органических соединений при помощи сорбционной трубки с последующей термодесорбцией и газохроматографическим анализом на капиллярных колонках. М. Стандартинформ, 2008. $32 \mathrm{c}$.

12. Ras M.R., Borrull F., Marce R.M. // Trends Anal. Chem. 2009. Vol. 28. No 3. pp. 347-361.

13. Методические указания МУК 4.1.147803. Определение фенола в атмосферном воздухе и воздушной среде жилых и общественных зданий методом высокоэффективной жидкостной хроматографии. $12 \mathrm{c}$.

14. Brown V.M., Crump D.R., Plant N. T., Pengelly I. // J. Chromatogr. A. 2014. Vol. 1350. pp. 1-9.

15. Березкин В.Г., Никитина Н.С. // Усnехи химии. 1971. Т. 40. № 5. С. 927-936.
16. Rodinkov, O.V., Bugaichenko A.S., Vlasov A.Yu. // Talanta. 2014. Vol. 119. pp. 407-411.

17. Родинков О.В., Вагнер Е.А., Бугайченко А.С., Москвин Л.Н. // Журн. аналит. химии. 2019. Т. 74. № 9. С. 673-678.

18. Родинков О.В., Москвин Л.Н. // Журн. аналит. химии. 2012. Т. 67. № 10. С. 908-916.

19. Плаченов Т.Г., Колосенцев С.Д. Порометрия. Л. Химия. $1988.176 \mathrm{c.}$

20. International Organization for Standardization, Pore size distribution and porosity of solid materials by mercury porosimetry and gas adsorption. Part 3: Analysis of micropores by gas adsorption (ISO Standard №15901-3:2007) $\mathrm{http} / / / \mathrm{www}$.iso.org/standard/40364.html.

21. Платонов И.А., Родинков О.В., А. Р. Горбачева А.Р. Москвин Л.Н. и др. // Журн. аналит. химии. 2018. Т. 73. № 2. С. 83-105.

22. Витенберг А.Г., Иоффе Б.В. Газовая экстракция в хроматографическом анализе: парофазный анализ и родственные методы. Л. Химия, 1982. 280 с.

23. Другов Ю.С., Родин А.А. Пробоподготовка в экологическом анализе. Практическое руководство. М. Бином, 2009. 856 с.

24. Медведев Е.И., Родинков О.В. // Сорбиионные и хроматографические прочессы. 2017. Т. 17. № 1. С. 110-116.

25. Гигиенический норматив ГН 2.1.6.3492-17. Предельно допустимые концентрации (ПДК) загрязняющих веществ в атмосферном воздухе городских и сельских поселений. М.: 2019. 57 с.

\title{
The choice of conditions for the sorption pre-concentration of phenols from the air stream on surface-layer carbon-fluoroplastic sorbents for their subsequent determination by HPLC
}

\author{
(C) 2020 Rodinkov O.V., Spivakovsky V., Moskvin L.N. \\ Saint Petersburg State University, Institute of Chemistry, Saint Petersburg
}

\begin{abstract}
Phenol and isomeric cresols are common highly toxic atmospheric air pollutants, the determination of which requires highly effective pre-concentration methods. The aim of this work is to select the conditions for express sorption pre-concentration of phenols from an air flow on surface-layer carbon-fluoroplastic sorbents for their subsequent HPLC determination at the level of maximum permissible concentrations. This aim is achieved by using surface-layer carbon-fluoroplastic sorbents. As the optimal carbon sorbent, FAD activated carbon was selected, which provides the maximum volumes of phenol retention from the flow of analysed air. To evaluate the effectiveness of the studied sorbents, model gas mixtures with a constant phenol concentration of $50 \mathrm{mg} / \mathrm{m}^{3}$ were used. These mixtures were obtained by passing the air flow through aqueous solutions with a known concentration of phenols. It was found that in the selected
\end{abstract}


range of volumetric air flow rates $(100-500) \mathrm{sm}^{3} / \mathrm{min}$, the equilibrium distribution of phenols between the phases and the constancy of their concentration in the gas phase during the experiment were ensured.

It was established that, ceteris paribus, the developed surface-layer sorbents can increase the concentration of phenols by a factor of 2-3 and reduce the duration of the sorption concentration stage by a factor of 1.5-2 compared to traditional volume-porous activated carbons. When implementing the analysis procedure, 15 litres of analysed air were passed through a sorption column at a flow rate of $0.5 \mathrm{dm}^{3} / \mathrm{min}$ for 30 minutes. Phenols were desorbed directly from the sorption column using $1.5 \mathrm{sm}^{3}$ of acetonitrile, which was analysed in a reverse phase HPLC with a fluorimetric detector. The lower limit of the range of determined concentrations of phenol and isomeric cresols was $2 \mu \mathrm{g} / \mathrm{m}^{3}$, and their MPC in atmospheric air was 10 and $5 \mu \mathrm{g} / \mathrm{m}^{3}$, respectively.

HPLC

Keywords: phenol, cresols, air, pre-concentration, sorbents, surface-layer, carbon-fluoroplastic,

\section{References}

1. Drugov Yu.S., Konopel'ko L.A., Popov O.G. Kontrol' zagrjaznenij vozduha zhilyh pomeshhenij, ofisov, administrativnyh i obshestvennyh zdanij. SPb., Nauka, 2013.302 p.

2. Poole C., Mester Z., Miró M., PedersenBjergaard S., Pawliszyn J., Pur. Appl. Chem., 2016, Vol. 88, No 7, pp. 517-558. DOI: 10.1515/pac-2015-0903

3. Woolfenden E., J. Chromatogr. A, 2010, Vol. 1217, pp. 2685-2694. DOI: 10.1016/j.chroma.2010.01.015

4. Piri-Moghadam H., Ahmadi F., Pawliszyn J., Trend. Anal. Chem., 2016., Vol. 85, pp. 133143. DOI: $10.1016 /$ j.trac.2016.05.029

5. Rodinkov O.V., Zhuravljova G.A., Analitika, 2019, Vol. 9, No 1, pp. 48-58. DOI: 10.22184/2227-572X.2019.09.1.48.58

6. Andrade-Eiroa A., Canle M., Leroy-Cancellieri V., Cerdà V., Trends Anal. Chem., 2016, Vol. 80, pp. 641-654. DOI: 10.1016/j.trac.2015.08.015

7. Płotka-Wasylka J., Szczepańska N., de la Guardia M., Namieśnik J., Trends Anal. Chem., 2016, Vol. 77, pp. 23-43. DOI: 10.1016/j.trac.2015.10.010

8. Mastrogiacomo A.R., Ottaviani M.F., Pierini E., Cangiotti M. et al., Chromatographia, 2002, Vol. 55, No 5,6, pp. 345-348 DOI: 10.1007/BF02491670

9. Postnov V.N., Rodinkov O.V., Moskvin L.N., Novikov A.G. et al., Uspekhi khimii, 2016, Vol. 85, No 2, pp. 115-138. DOI: 10.1070/RCR4551

10.Zhejvot V.I., Zhurn. analit. khimii, 2006, Vol. 61, No 9, pp. 832-852 DOI: $10.1134 / \mathrm{S} 1061934806090024$

11.GOST R ISO 16017-1-2007. Vozduh atmosfernyj, rabochej zony i zamknutyh pomeshhenij. Otbor prob letuchih organicheskih soedinenij pri pomoshhi sorbcionnoj trubki $\mathrm{s}$ posledujushhej termodesorbciej i gazohromatograficheskim analizom na kapilljarnyh kolonkah, M., Standartinform, 2008, 32 p.

12.Ras M.R., Borrull F., Marce R.M., Trends Anal. Chem., 2009, Vol. 28, No 3, pp. 347-361. DOI: 10.1016/j.trac.2008.10.009

13. Metodicheskie ukazanija MUK 4.1.147803. Opredelenie fenola $v$ atmosfernom vozduhe i vozdushnoj srede zhilyh i obshhestvennyh zdanij metodom vysokojeffektivnoj zhidkostnoj hromatografii. $12 \mathrm{p}$.

14.Brown V.M., Crump D.R., Plant N.T., Pengelly I., J. Chromatogr. A, 2014, Vol. 1350, pp. 1-9. DOI: 10.1016/j.chroma.2014.05.011

15.Berezkin V.G., Nikitina N.S., Uspekhi khimii, 1971, Vol. 40, No 5, pp. 927-936.

16.Rodinkov O.V., Bugaichenko A.S., Vlasov A.Yu., Talanta, 2014, Vol. 119, pp. 407-411. DOI: 10.1016/j.talanta.2013.11.040

17.Rodinkov O.V., Vagner E.A., Bugajchenko A.S., Moskvin L.N., Zhurn. analit. khimii, 2019, Vol. 74, No 9, pp. 877882. DOI: $10.1134 / \mathrm{S} 1061934819090089$

18. Rodinkov O.V., Moskvin L.N., Zhurn. analit. khimii, 2012, Vol. 67, No 10, pp. 814822. DOI: $10.1134 / \mathrm{S} 1061934812100073$

19.Plachenov T.G., Kolosencev S.D. Porometrija, L., Khimija, 1988, 176 p.

20.International Organization for Standardization, Pore size distribution and porosity of solid materials by mercury porosimetry and gas adsorption. Part 3: Analysis of micropores by gas adsorption (ISO Standard №15901-3:2007) http://www.iso.org/standard/40364.html.

21.Platonov I.A., Rodinkov O.V., Gorbacheva A.R., Moskvin L.N. et al., Zhurn. analit. khimii, 2018, Vol. 73, No 2, pp. 109-127. DOI: 10.1134/S1061934818020090

22.Vitenberg A.G., Ioffe B.V. Gazovaja jekstrakcija $\mathrm{v}$ hromatograficheskom analize: 
parofaznyj analiz i rodstvennye metody, L., Khimija, 1982, 280 p.

23.Drugov Yu.S., Rodin A.A. Probopodgotovka $\mathrm{V}$ jekologicheskom analize. Prakticheskoe rukovodstvo, M., Binom, 2009, 856 p.

24.Medvedev E.I., Rodinkov O.V., Sorbtsionnye i khromatograficheskie protsessy, 2017, Vol. 17, No 1, pp. 110-116.

Родинков Олег Васильевич - профессор кафедры аналитической химии, д.х.н., СанктПетербургский государственный университет, Институт химии, Санкт-Петербург

Спиваковский Валерий - стажер-исследователь, Санкт-Петербургский государственный университет, Институт химии, Санкт-Петербург

Москвин Леонид Николаевич - профессор кафедры аналитической химии, д.х.н., Санкт-Петербургский государственный университет, Институт химии, Санкт-Петербург
25. Gigienicheskij normativ GN 2.1.6.349217. Predel'no dopustimye koncentracii (PDK) zagrjaznjajushhih veshhestv $\mathrm{v}$ atmosfernom vozduhe gorodskih i sel'skih poselenij. M., 2019, $57 \mathrm{p}$.

Rodinkov Oleg Vasilievich - Professor, Department of Analytical Chemistry, Doctor of Chemical Sciences, St. Petersburg State University, Institute of Chemistry, St. Petersburg

Spivakovskyi Valerii - trainee researcher, St. Petersburg State University, Institute of Chemistry, St. Petersburg

Moskvin Leonid Nikolaevich - Professor, Department of Analytical Chemistry, Doctor of Chemistry, St. Petersburg State University, Institute of Chemistry, St. Petersburg 